\title{
Apreciación artística: Herramienta interdisciplinaria para un desarrollo cognitivo en la educación
}

\section{Appreciation: Interdisciplinary tool for cognitive development in education}

Mgs. Rosa Armijos Acosta

Dra. Ketty Herrera Rivas

Universidad de Guayaquil, Ecuador

Autor para correspondencia: keila.herrerar@ug.edu.ec, rosa.armijosa@ug.edu.ec

Fecha de recepción: 01 de Septiembre de 2016 - Fecha de aceptación: 01 de Noviembre de 2016

Resumen: Esta investigación tiene como objetivo general reconocer la influencia que ejerce la apreciación artística en la aproximación al desarrollo creativo y cognitivo del individuo. Estudios recientes han establecido que la apreciación artística estimula el pensamiento y la imaginación, a más de esto cuando se menciona la filosofía del arte se habla del amor, la belleza y las emociones, estos criterios de alguna manera ejercen un poder creativo en el diletante y es así que el arte en su contemplación se va construyendo el pensamiento y la comprensión. Nos preguntamos si a través de la apreciación artística donde intervienen símbolos y signos artísticos creados que se perciben y funcionan como un todo permite desarrollar procesos básicos del pensamiento, sean estos la observación, imaginación, comparación, relación, análisis, entre otros. Para responder a esta interrogante, estudiamos algunas teorías de expertos y los efectos en este trabajo se describirán los resultados de la investigación donde se aplicó un modelo de diagnóstico que permitió identificar su situación en cuanto a la idea y valoración del arte como medio transversal enriquecedor en la enseñanzas de cualquier asignatura. La investigación se realizó dentro del paradigma cualitativo para la interpretación de los resultados, sin descartar el apoyo cuantitativo para un diseño experimental. Tras el análisis de la información se consideró que las actividades extracurriculares relacionadas a través del arte y la cultura influye de manera significativa en el desarrollo cognitivo del estudiante para lograr adquirir un aprendizaje significativo y propio.

Palabras claves: apreciación artística; educación; desarrollo cognitivo

Abstract: This research has the general objective to recognize the influence of artistic appreciation in the approach to creative and cognitive development of the individual. Recent studies have established that artistic appreciation stimulates thinking and imagination more than this when the philosophy of art is about love, beauty and emotions mentioned, these criteria somehow exert a creative power in the dilettante and so that art in contemplation is built thinking and understanding. We wondered whether through artistic appreciation which involved art symbols and created signs that are perceived and function as a whole can develop basic thought processes, whether observation, imagination, comparison, relation, analysis, among others. To answer this question, we examined some theories of experts and effects in this paper the results of research where a diagnostic model that identified the situation regarding the idea and appreciation of art as an enriching cross medium is applied will be described the teaching of any subject. The research was conducted within the qualitative paradigm for the interpretation of results, without discarding the quantitative support for an experimental design. After analyzing the information it was considered 
that extracurricular activities through art and culture has a significant influence on cognitive development of the student to achieve a cognitive acquire and own learning.

Key words: artistic appreciation; education; cognitive development

\section{Introducción}

El nivel cultural alcanzado por el estudiante universitario previo a su registro en cualquier unidad educativa superior, y en específico el logrado en el ámbito cultural, artístico y social influye de manera significativa en su desarrollo intelectual y emocional a lo largo de su carrera. Esta articulación de nivel cultural y el dominio de los más variados aspectos se hacen clave en el desenvolvimiento de los futuros profesionales." El desafío de la educación artística consiste en modular eficaz los valores de la cultura, los medios disponibles para la educación en las artes y para la evaluación, y para los particulares perfiles individuales y de desarrollo de los estudiantes a educar". (H.Gardner, 2011).

El arte como recurso didáctico de tipo viso-sensorial permite experimentar aspectos diversos en el sentir del individuo, sean estos sociales, religiosos, políticos históricos, filosófico. El acervo cultural determina y se muestra en el desarrollo expresivo, reflexivo y crítico del individuo, de tal motivo que esta se manifiesta como una condición del aprendizaje significativo, "Un aprendizaje es significativo cuando los contenidos: Son relacionados de modo no arbitrario y sustancial (no al pie de la letra) con lo que el alumno ya sabe. Por relación sustancial y no arbitraria se debe entender que las ideas se relacionan con algún aspecto existente específicamente relevante de la estructura cognoscitiva del alumno, como una imagen, un símbolo ya significativo, un concepto o una proposición” (Ausubel, 1983 :18), entonces a manera de ejemplo conocer, apreciar y valorar el arte en sus diversas manifestaciones, y esto vincularlo con conceptos relevantes, transformándolos en enseñanzas significativas para que el estudiantes se apropia de ellos.

En este contexto surge la necesidad de presentar una propuesta sobre la importancia de conocer el arte y que este sea apreciado desde el punto de vista pedagógico para el desarrollo cognitivo en los estudiantes de cualquier nivel educativo.

\section{Desarrollo}

Observaciones realizadas, acordes a los principios científicos establecidos para el caso, se ha podido detectar en estudiantes tanto del nivel primario, secundario y superior, que cuando se les plantea una problemática relacionada con el arte y la cultura, sus aportaciones son no solo mínimas, sino vagas y pobres, esto se debe al poco conocimiento o la mala información de este tema, de tal motivo resulta difícil, cuando no imposible, sostener diálogos relacionados con el quehacer artístico, reconocer los diferentes géneros y estilos y/o arquitectónicos, realizar críticas con criterios de valor estético, cultural, y más aún lograr que los estudiantes presenten propuestas innovadoras.

Tal situación es consecuencia de una educación escolar -comprende la escuela y el colegio-, en la cual se hallaron ausentes las actividades curriculares o extracurriculares vinculadas con el arte y la cultura. Súmese a ello lo muy poco que hacen todavía en ese sentido 
la familia y la sociedad, como resultado, los estudiantes con frecuencia carecen de elementos que les permitan reconocerse y conectarse con su pasado y entender quiénes son.

Es de interés reflexionar acerca de la importancia de incluir en los programas iniciales de educación, como en los demás grados de estudio, actividades relacionadas con el arte y la cultura, con la producción y consumo del arte, a fin de que cuando los estudiantes lleguen a las aulas universitarias sean capaces de valorar, apreciar y sostener criterios críticos sobre los productos de la cultura y las artes,. Es importante estar consciente que la mayoría de los establecimientos educativos no cuentan con docentes especializados en arte que ayuden a cumplir estos objetivos curriculares, por general, estas asignaturas son impartidas por docentes de especialidades muy lejanas al ámbito artístico lo cual influye en el estudiante de manera directa o indirecta.

Es trascendental sensibilizar con responsabilidad a nuestros estudiantes; en la Declaración de los Derechos Humanos de la Organización de las Naciones Unidas señala que: "Según las investigaciones realizadas cuando una persona en fase de aprendizaje entra en contacto con procesos artísticos y recibe una enseñanza que incorpora elementos de su propia cultura, esto estimula su creatividad, su imaginación, su inteligencia emocional y además le dota de una orientación moral", el resultado de esta investigación justifica la importancia de incorporar actividades artísticas culturales que complementen el aprendizaje en todos los niveles de educación, influenciar positivamente en el sentir y crecimiento personal de los estudiantes, este crecimiento, mínimo, se obtendría mediante la apreciación y complacencia que brindan los museos, galerías teatros, actos públicos y privados artísticos, entre otros.

A través de la apercepción se cultiva el gusto estético que desarrolla la sensibilidad, la criticidad, poder involucrar el concepto de belleza, comenzando en los niños y niñas, si ello se lograra, cuando lleguen a la Universidad, serían capaces de desarrollar proyectos de identidad visual, sostener conversaciones con un alto sentido crítico y analítico, mantener el concepto de belleza en el actuar diario, esto conlleva a la reflexión de la complementación que requiere la formación de los profesionales ya que sus conocimientos tienen alcances culturales particulares y sociales.

La apreciación artìstica es un mecanismo básico para una educación integral, según Megalia Werba "La educación de la sensibilidad es la vía ideal para potenciar todas las operaciones mentales del sujeto. El desarrollo de la sensibilidad implica aumentar la capacidad de reconocimiento y discriminación de formas, colores, volúmenes, ...y sus relaciones." (Magali Werba-Claudia Hoffnung-Rosina Singer, 2004), la capacidad creativa trae consigo la capacidad de inventiva. "Para el fomento de la creatividad, la actividad artística tiene un papel destacado, ya que requiere ejercitar el impulso creador y no la reproducción mecánica de lo ya conocido." (Magali Werba-Claudia Hoffnung-Rosina Singer, 2004).

Respecto a la producción y el "consumo" del arte constituyen una necesidad espiritual del individuo y la sociedad, ambas se funden de forma universal; tanto por lo cosmopolita de su presencia en todas las sociedades, como por los similares intercambios culturales que a partir de la creación y el goce estético se da, ambas también llevan contenidas en sí mismas, funciones y finalidades idénticas por su contenido pero diferentes por su forma de expresión. 
La posesión o no de determinado desarrollo del goce estético está en relación directa con la educación artística recibida. Una buena educación artística garantiza que los estudiantes enfrenten con mucha más preparación e interés el proceso de enseñanza ya que esta puede tornarse significativa no solo en lo profesional sino en el diario vivir. Un estudiante capaz de apreciar el arte -goce estético-, se halla en mejores condiciones para realizar sus estudios.

El hecho de que pueda imaginar, crear y disfrutar, a partir y a través del arte, favorecerá sus estudios, el arte sensibiliza lo que permite que se produzca un proceso de desarrollo mental más flexible, lo cual en un futuro le ayudará a resolver los problemas que ante sí surjan y poderlos resolver de forma creativa, tanto en el ámbito profesional y como en los más diversos aspectos de su vida.

El desafío de la educación artística que menciona Gardner en su libro “Arte, mente y cerebro" se direcciona a contrastar la producción y la actividad artística basada con el conocimiento, la actitud, la capacidad de goce estético y el desempeño de los estudiantes a partir de ello.

Las artes fomentan la curiosidad por el conocimiento; se piensa de manera visual, el conocimiento y el goce estético permiten dominar y expresar percepciones, sentimientos y concepciones del mundo. Uno de los beneficios derivados del conocimiento y el goce estético es que dota al individuo de una mayor capacidad de expresión y le desarrolla destrezas de razonamiento espacial-temporal, necesarias para el manejo de ideas y conceptos.

En el caso particular de los alumnos de carreras pertenecientes o relacionadas con el ámbito artístico, en cualquiera de sus manifestaciones, los resultados derivados de tal contrastación indican cuán preparado o no se halla el estudiante para la carrera que en particular cursa. En general un estudiante de nivel superior como lo exige el momento que estamos viviendo debe estar preparado para que:

1- Sean profesionales capaces de dar respuestas creativas e innovadoras en su campo profesional.

2- Tengan una mentalidad positiva, crítica y emprendedora, dueños de técnicas convencionales

3- Participen en equipos multidisciplinarios en proyectos tecnológicos y culturales, en planificación estratégica y desarrollo de soluciones de índole cultural, político y social.

4- Sean capaces de interactuar en equipo junto a profesionales de diversas áreas.

\section{Contexto y objetivo de la experiencia}

Durante un siclo de estudio, en la asignatura de Semiótica, Expresión artística, Filosofía de la comunicación, se aplicó metodología cualitativa, basada en el aprendizaje a través actividades extracurriculares, donde los estudiantes debían realizar visitas a museos, galerías, parques, cementerios, iglesias, asistir a conversatorios de expertos en arte, realizar entrevistas artistas y gestores culturales, para luego contrastar con los temas expuestos en clase, así poder debatir e interpretar las diferentes corrientes artísticas de cada época, los sucesos que se han ido marcando en la historia. 
Se pudo observar que cuando se conoce los orígenes de una cultura esta es valorada, se propicia a la reflexión, al análisis, despierta la curiosidad por conocer más. Se logró cumplir uno de los objetivos fundamentales: propiciar que los estudiantes potencien las habilidades cognitivas y desarrollar el pensamiento creativo, crítico y analítico, y que el aprendizaje sea significativo, "es el proceso a través del cual una nueva información (un nuevo conocimiento) se relaciona de manera no arbitraria y sustantiva (no lineal) con la estructura cognitiva de la persona que aprende" (Moreira)

\section{Metodología}

Por su naturaleza este trabajo de investigación tuvo un enfoque de carácter cualitativo por que no buscó las causas del problema de estudio, sino su comprensión desde una realidad dinámica. Se realizaron entrevistas a expertos del arte y encuestas a estudiantes antes y después de la investigación. El propósito de esta investigación no fue encontrar las acusas y efectos ya que el problema investigativo estuvo influenciado por una serie de variables del contexto por ejemplo: la familia, la cultura, la sociedad.

\section{El universo de la muestra}

El universo es de 450 estudiantes universitarios de diferentes horarios de estudio en edades que fluctúan entre los 17 y 20 años de edad, con su correspondiente muestra de 226 estudiantes

\section{Conclusiones}

La experiencia docente profesional, empírica, indica que resulta imposible satisfacer las múltiples necesidades de educación artística con que se matriculan los estudiantes. Ello se confirmó de manera científica mediante entrevistas realizadas a cuatro profesores que imparten las asignaturas de Historia del Arte, Semiótica, Expresión Artística, Expresión Gráfica.

La urgencia de la necesidad de satisfacer la ausencia de una mínima educación artística en los estudiantes es apreciable también a partir de los resultados de una encuesta aplicada a los alumnos de la Carrera de Diseño Gráfico en la Facultad de Comunicación Social de la Universidad de Guayaquil.

Resulta un indicador, la importancia de realizar actividades extracurriculares incorporadas de guías didácticas desde la escuela para así cultivar la apreciación y el gusto estético, lo que garantizará el desarrollo del pensamiento estético.

El perfil de todo profesional tiene que cumplir las exigencias del mundo actual no solo para triunfar en lo profesional, sino en el diario vivir, Gardner en su libro "Las cinco mentes del futuro" asevera que " no solamente es importante triunfar como individuo, sino que el mundo además de esto, necesita de personas con mentes creativas, respetuosas, disciplinadas, sintéticas y éticas, indispensables características de seres que deseen vivir en armonía y responder a las exigencias actuales que demandan el mundo de hoy". 
Es necesario poder ddesarrollar un sistema de actividades extracurriculares -el cual se propone a continuación-, dirigido a dotar de una mínima educación artística

Dicho sistema de actividades extracurriculares deberá incluir:

1- Un ciclo de lecturas comentadas de literatura universal en las cuales aparezcan elementos de las artes plásticas.

2- Un ciclo de películas de la más alta calidad que incluya conocimientos sobre la vida y la obra de grandes creadores, con derivación fundamental a los artistas de la plástica universal.

3- Visitas regulares a bibliotecas, museos.

4- Visitas regulares a los teatros y .eventos culturales

5- Encuentros con creadores de la plástica.

6- Asistencia regular a la inauguración de las exposiciones de artistas plásticos nacionales y extranjeros

\section{Bibliografía}

Eisner W. Elliot. (1995) Educar la visión artística. Paidos Educador. Barcelona: España

Francesco de Bartolomeis (2001). El color de los pensamientos y de los sentimientos. España: Ediciones Octaedro

García, Antonio Stalin (2005). Enseñanza y aprendizaje en la educación artística. El Artista , 2. pp. 80-97.

Howard Gardner (2011) Arte, mente y cerebro: una aproximación cognitiva a la creatividad. Barcelona: Paidós.

Howard Gardner (2011). Las cinco mentes del futuro. Barcelona: Paidós.

Lineamientos curriculares de Educación artística, Ecuador,

Perkins, D. (1997). "La escuela inteligente" del adiestramiento de la memoria a la educación de la mente Barcelona. editorial GEDISA 